\title{
Senescência pós-colheita de inflorescências de esporinha (Consolida ajacis)
}

Fernando Luiz Finger ${ }^{(1)}$, Tânia Forster Carneiro(2) e José Geraldo Barbosa(1)

(1)Universidade Federal de Viçosa (UFV), Dep. de Fitotecnia, CEP 36571-000 Viçosa, MG. E-mail: ffinger@ufv.br, jgeraldo@ufv.br (2)UFV, Dep. de Biologia Vegetal, CEP 36571-000 Viçosa, MG. E-mail: taniafoster@hotmail.com

Resumo - O objetivo deste trabalho foi avaliar a influência de inibidores da ação e síntese de etileno sobre a longevidade, respiração e produção de etileno em inflorescências de Consolida ajacis Nieuwl. As hastes foram colhidas e imediatamente condicionadas em $5 \%$ de sacarose e em $1 \mathrm{mM}$ de tiossulfato de prata (STS) em combinação, ou não, com 5\% de sacarose por 30 minutos, e pulverizadas com 0,5, 1,0, 1,5 e 2,0 mM de ácido aminooxiacético (AOA) e com 5, 10, 15 e 20 mM de ácido acetilsalicílico (AAS). A senescência da flor de $C$. ajacis foi caracterizada pela produção climatérica de etileno e $\mathrm{CO}_{2}$, que atingiu níveis máximos aos seis dias após a colheita, coincidentes com os estádios tardios da abscisão e murchamento das flores. A longevidade prolongouse 2,46 vezes nas flores condicionadas com $1 \mathrm{mM}$ de STS. Porém, a adição de 5\% de sacarose ao STS reduziu a longevidade das flores. O condicionamento das hastes com 5\% de sacarose ou pulverização com $2 \mathrm{mM}$ de AOA e $20 \mathrm{mM}$ de AAS não prolongou a longevidade ou inibiu a respiração e o etileno climatéricos. O STS foi efetivo em reduzir a respiração e a produção de etileno.

Termos para indexação: condicionamento, longevidade, etileno, respiração.

\section{Postharvest senescence of Consolida ajacis inflorescences}

Abstract - This work had the objective of evaluating the influence of inhibitors of ethylene action and synthesis on the longevity, respiration and ethylene production of Consolida ajacis Nieuwl. inflorescences. The inflorescences were harvested and immediately pulsed with $5 \%$ sucrose, $1 \mathrm{mM}$ silver thiosulfate (STS) combined or not with 5\% sucrose for 30 minutes or sprayed with $0.5,1.0,1.5$ and $2.0 \mathrm{mM}$ aminooxiacetic acid (AOA) and 5, 10,15 and $20 \mathrm{mM}$ acetylsalicylic acid (ASA). Flower senescence of $C$. ajacis was characterized by the presence of climacteric ethylene and $\mathrm{CO}_{2}$ production, reaching maximal evolution at the sixth day after harvest, which were coincident with the later phases of the flower abscission and wilting. Longevity of flowers pulsed with $1 \mathrm{mM} \mathrm{STS}$ increased by 2.46-fold compared to control flowers. However, when STS was mixed with 5\% sucrose, a decrease on longevity was observed. Pulsing the flowers with 5\% sucrose or spraying with $2 \mathrm{mM}$ AOA or $20 \mathrm{mM}$ ASA neither increased the longevity nor inhibited the climacteric respiration and ethylene production. The treatment with STS was effective in reducing the respiration and ethylene evolution by the flower.

Index terms: pulsing, longevity, ethylene, respiration.

\section{Introdução}

Consolida ajacis Nieuwl. é uma inflorescência conhecida como esporinha, pertencente à família Ranunculaceae, e semeada, geralmente, no outono para florescer no final do inverno e início da primavera. Apresenta crescimento rápido, adaptando-se ao cultivo de pleno sol (Lorenzi \& Souza, 1999). Por ser uma espécie altamente sensível ao etileno, ocorre rápida senescência e abscisão das flores colhidas (Nowak \& Rudnicki, 1990). Portanto, a comercialização dessa inflorescência como flor de corte é limitada por sua curta longevidade, que pode ser inferior a dois dias em condições de elevada temperatura ambiente (Finger et al., 2001).

O etileno é um regulador de crescimento que promove uma série de respostas fisiológicas nas plantas, e sua ação está associada à indução da senescência natural das flores. As flores pertencentes às famílias Geraniaceae, Labiatae, Ranunculaceae, Rosaceae e Scrophulariaceae, quando expostas a concentrações ativas de etileno, entre 0,1 e $1,0 \mu \mathrm{L} \mathrm{L}^{-1}$, apresentam acelerada abscisão das pétalas ou flores (Woltering \& Doorn, 1988). Em espécies florais sensíveis ao etileno, 
como cravos, Lathyrus e Delphinium, a longevidade de vaso é estendida em tratamentos com compostos inibidores da ação do etileno (Veen, 1983; Mor et al., 1984; Woltering \& Doorn, 1988). O íon de prata $\left(\mathrm{Ag}^{+}\right)$ é eficiente em bloquear a ação do etileno em diversas flores, especialmente quando aplicado na forma de tiossulfato de prata (Abeles et al., 1992). O tratamento com tiossulfato de prata prolonga a vida em vaso de muitas flores de corte, como observado em Lathyrus (Ichimura \& Hiraya, 1999) e Petunia (Borochov et al., 1997).

O ácido aminooxiacético e o ácido acetilsalicílico são inibidores da síntese do etileno com potencial para utilização como componentes de soluções preservativas florais. O ácido aminooxiacético é inibidor da sintase do ACC, enzima responsável pela conversão do composto S-adenosil-L-metionina (SAM) para 1-aminociclopropano-1-ácido carboxílico (Altvorst \& Bovy, 1995). O tratamento com ácido aminooxiacético é eficiente em reduzir a respiração, produção de etileno e elevar a vida em vaso das flores de orquídeas do gênero Phalaenopsis (Woltering, 1987; Porat et al., 1995) e Cymbidium (Goh et al., 1985) e de Dianthus (Bichara \& Staden, 1993; Uda et al., 1997). Em algumas variedades de Rosa hybrida, a utilização de solução de vaso com sacarose a $5 \%$ mais $0,5 \mathrm{mM}$ de ácido aminooxiacético aumenta significativamente a vida em vaso (Ketsa \& Narkbua, 2001). O uso de ácido acetilsalicílico pode aumentar a vida em vaso das flore pelo bloqueio da conversão do ACC em etileno, via inibição da atividade da oxidase do ACC (Leslie \& Romani, 1986).

O controle da senescência das flores de corte é um processo que varia entre espécies e requer a otimização das relações hídricas, redução da abscisão ou murchamento das pétalas e flores, controle do crescimento dos microrganismos, e em muitos casos, o fornecimento de substratos respiratórios.

O objetivo deste trabalho foi avaliar a influência de inibidores da ação e da síntese de etileno sobre a longevidade, respiração e produção de etileno em inflorescências de C. ajacis.

\section{Material e Métodos}

As flores de C. ajacis foram colhidas no campo de cultivo do Departamento de Fitotecnia da Universidade Federal de Viçosa, Viçosa, MG, no período da manhã A colheita foi realizada quando 1/3 das flores estavam em fase de botão, 1/3 em fase de abertura floral e $1 / 3$ completamente abertas e com cor das pétalas definida (Finger et al., 2001). As inflorescências foram imediatamente transportadas para o laboratório, selecionadas, uniformizadas por tamanho $(40 \pm 5 \mathrm{~cm}$ de comprimento) e divididas ao acaso nos experimentos. Os experimentos foram realizados em temperaturas de $24 \pm 1^{\circ} \mathrm{C}$, umidade relativa de $60 \pm 20 \%$ e intensidade luminosa de $10 \mu \mathrm{mol} \mathrm{m}{ }^{-2} \mathrm{~s}^{-1}$. Após os tratamentos, as inflorescências foram mantidas em vasos com água destilada, renovada a cada dois dias.

Diariamente foram avaliadas as taxas de abscisão e senescência floral (murchamento), e quantificou-se a produção de etileno e de $\mathrm{CO}_{2}$ pelas flores. $\mathrm{O}$ término da longevidade das inflorescências ocorreu quando houve mais que $50 \%$ de abscisão e murchamento das flores (Finger et al., 2001).

Inflorescências de esporinha foram pulverizadas com soluções aquosas de ácido aminooxiacético (AOA) nas concentrações de $0,0,5,1,0,1,5$ e 2,0 mM ou com ácido acetilsalicílico (AAS) nas concentrações de $0,5,10,15$ e $20 \mathrm{mM}$ até o completo molhamento das hastes. Outro lote de inflorescência foi submetido a soluções de condicionamento por 30 minutos com sacarose a $5 \%, 1 \mathrm{mM}$ de STS combinado com sacarose a 5\%, $1 \mathrm{mM}$ de STS ou água destilada (controle). Após o condicionamento, as hastes foram transferidas para vasos com água destilada, trocada a cada dois dias. Utilizou-se o delineamento experimental inteiramente casualizado com cinco repetições e cinco hastes por vaso.

Diariamente flores individuais foram destacadas, pesadas e colocadas em frascos de 9,8 mL que, em seguida, foram lacrados. Após um período de 30 minutos, foram retiradas amostras da atmosfera interna dos frascos para a determinação do $\mathrm{CO}_{2}$ e, após uma hora e meia, para quantificação do etileno. A quantificação da produção de etileno e de $\mathrm{CO}_{2}$ foi realizada em cromatógrafo a gás equipado com coluna Porapak $\mathrm{Q}$ e detector de ionização de chama para o etileno e condutividade térmica para o $\mathrm{CO}_{2}$. Utilizou-se o delineamento experimental inteiramente casualizado, com três repetições e no mínimo duas flores por frasco.

Os dados foram submetidos à análise de variância ANOVA e as médias comparadas pelo teste de Tukey, a $5 \%$ de probabilidade.

\section{Resultados e Discussão}

A pulverização das flores com 0,5, 1,0, 1,5 e 2,0 mM de AOA ou 5, 10, 15 e $20 \mathrm{mM}$ de AAS não influenciou a longevidade em relação às inflorescências do controle. 
A longevidade média das flores foi de 6,5 dias, independentemente da concentração aplicada, porém o AOA e o AAS foram efetivos em retardar o início da abscisão. Nas flores tratadas com AOA, houve redução da abscisão de $24,9 \%$ para $4,8 \%$ no quarto dia após o tratamento. No entanto, no sexto dia, as taxas de abscisão foram semelhantes às do tratamento controle $(70,6 \%)$. Comportamento semelhante foi observado nas flores tratadas com AAS, em que, no quarto dia, a abscisão fo de 3,8\% nas flores tratadas e 12,0\% nas flores controle.

Em orquídeas do gênero Cattleya, tratadas com AOA (Goh et al., 1985), houve efeito similar ao encontrado no presente trabalho, porém, em Limonium, o tratamento com AOA causou escurecimento nas hastes florais inibiu a abertura floral (Shimamura et al., 1997). Segundo Malamy \& Klessing (1992), dependendo da concentração utilizada e da capacidade de resposta da flor, o AAS pode interferir nos íons transportados pela membrana e induzir rápida despolarização e colapso do potencial eletroquímico da membrana, abscisão das folhas e indução do fechamento dos estômatos.

A pulverização das hastes com $2 \mathrm{mM}$ de AOA $20 \mathrm{mM}$ de AAS ou o condicionamento das hastes por 30 minutos com solução de sacarose a $5 \%$ não resultaram em alteração da longevidade em relação às flores do controle (Figura 1). Em rosas, cuja flor é considerada insensível ao etileno, a adição de AOA na água do

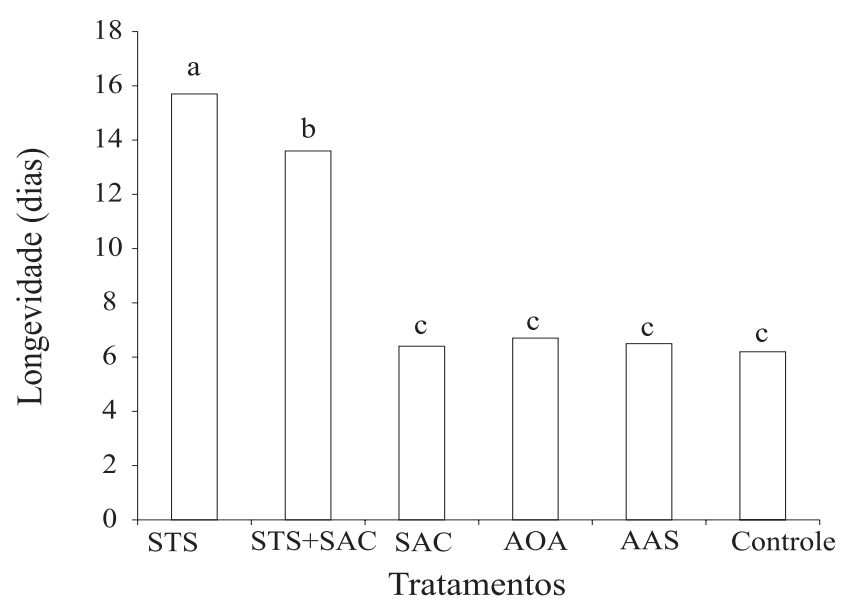

Figura 1. Longevidade de inflorescências de esporinha (Consolida ajacis) condicionadas com $1 \mathrm{mM}$ de tiossulfato de prata (STS), $1 \mathrm{mM}$ de STS + 5\% de sacarose (SAC), $5 \%$ de sacarose por 30 minutos ou pulverizadas com $2 \mathrm{mM}$ de ácido aminooxiacético (AOA) e $20 \mathrm{mM}$ de ácido acetilsalicílico (AAS). Colunas com mesma letra não diferem entre si pelo teste de Tukey, a 5\% de probabilidade. vaso aumentou a longevidade da flor, quando foi associada à presença de sacarose, porém, a efetividade do AOA foi dependente do $\mathrm{pH}$ da solução (Ketsa \& Narkbua, 2001). Os mesmos autores observaram que o pH de 2,9 da solução contendo 0,5 mM AOA e 5\% de sacarose teve menor população de bactérias, permitiu maior absorção de água pela haste e reduziu a incidência de pescoço torcido. Estes resultados sugerem que o AOA afeta outros aspectos da fisiologia da flor, não relacionados diretamente com inibição da produção de etileno, como melhoria do balanço hídrico decorrente da não obstrução dos vasos xilemáticos das hastes cortadas (Ketsa \& Narkbua, 2001)

O condicionamento das hastes com solução de $1 \mathrm{mM}$ de STS por 30 minutos elevou a longevidade das flores em 2,46 vezes comparado ao do tratamento controle. Porém, a adição de 5\% de sacarose à solução de $1 \mathrm{mM}$ de STS reduziu a longevidade das flores de 16 dias para 13,6 dias (Figura 1). Portanto, nesta espécie, não houve efeito aditivo do STS e da sacarose, aplicados na forma de solução de condicionamento, sobre a vida de vaso das inflorescências.

A interação da sacarose e do STS também foi avaliada em flores de Lathyrus (Mor et al., 1984; Ichimura \& Hiraya, 1999) e Gladiolus por Serek et al. (1994). Nestes trabalhos também houve maior longevidade naquelas flores tratadas com STS quando comparada ao tratamento de STS mais sacarose. Em flores de Lathyrus, o tratamento com sacarose estimulou a produção autocatalítica de etileno, e em Gladiolus, o STS aplicado isoladamente foi capaz de superar a deficiência de carboidratos na indução de abertura floral. Em flores altamente sensíveis ao etileno, como Alstromeria, o condicionamento com $2 \mathrm{mM}$ de STS por três horas, seguido de transferência das hastes para uma solução de vaso contendo $1 \%$ de sacarose, não elevou a longevidade da flor comparado ao tratamento apenas com STS (Chanasut et al., 2003). Portanto, a efetividade da sacarose em elevar a longevidade das flores é altamente dependente da espécie, sendo este tratamento mais efetivo no estímulo à abertura das flores e aumento da absorção de água pela flor. $\mathrm{O}$ aspecto geral das inflorescências de esporinha, aos seis dias após a colheita, tratadas ou não com $5 \%$ de sacarose, $5 \%$ de sacarose $+1 \mathrm{mM}$ de STS e $1 \mathrm{mM}$ de STS evidencia a acentuada abscisão nas flores do controle e nas condicionadas com 5\% de sacarose (Figura 2). 
A flor de esporinha do controle e aquelas tratadas com 5\% de sacarose, $2 \mathrm{mM}$ de AOA e $20 \mathrm{mM}$ de AAS apresentaram aumento tipicamente climatérico quanto à respiração e produção de etileno com o desenvolvimento da senescência das pétalas (Figuras 3 e 4). Nestas flores, o aumento acentuado e persistente da produção de etileno iniciou-se entre o primeiro e segundo dia após a colheita, enquanto o aumento na produção de $\mathrm{CO}_{2}$ ocorreu entre o segundo e quarto dia, respectiva-

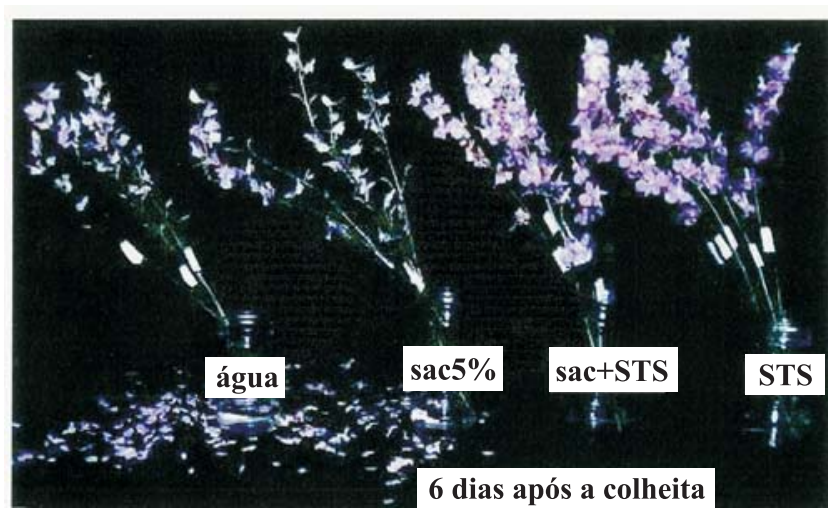

Figura 2. Aparência das inflorescências de esporinha (Con solida ajacis) seis dias após tratamento com soluções de condicionamento contendo 5\% de sacarose (SAC), $1 \mathrm{mM}$ de tiossulfato de prata (STS) $+5 \%$ de sacarose e $1 \mathrm{mM}$ de STS por 30 minutos.

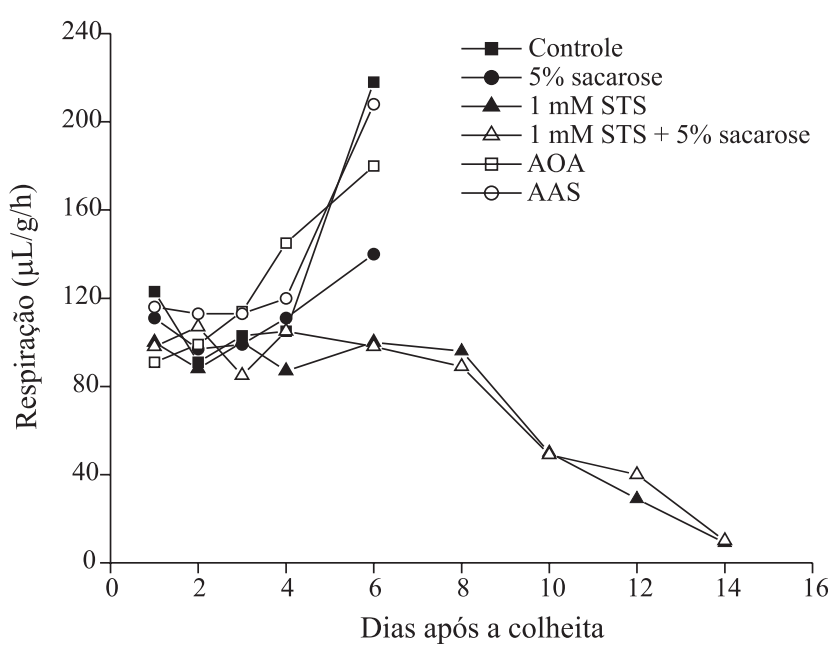

Figura 3. Produção de $\mathrm{CO}_{2}$ em flores de esporinha (Consolida ajacis) após o condicionamento com 5\% de sacarose, $1 \mathrm{mM}$ de tiossulfato de prata (STS) ou $1 \mathrm{mM}$ de STS $+5 \%$ sacarose por 30 minutos, e pulverizações com $2 \mathrm{mM}$ de ácido aminooxiacético (AOA) e $20 \mathrm{mM}$ de ácido acetilsalicílico (AAS). mente. Porém, uma vez iniciado o climatério da flor, não foi observada uma fase pós-climatérica caracterizada pela queda da produção de etileno e do $\mathrm{CO}_{2}$ até a murcha completa das pétalas aos seis dias após a colheita.

O condicionamento com soluções de $1 \mathrm{mM}$ de STS e de $1 \mathrm{mM}$ de STS + 5\% de sacarose inibiu o aumento climatérico da respiração e da produção de etileno das flores, comparado ao controle (Figuras 3 e 4). No entanto, nos tratamentos de condicionamento com $5 \%$ de sacarose, e pulverizações com $2 \mathrm{mM}$ de AOA e $20 \mathrm{mM}$ de AAS, o padrão de elevação de etileno e $\mathrm{CO}_{2}$ foi semelhante ao das flores controle.

Houve uma relação inversa entre a longevidade das flores e a evolução da produção de etileno e da respiração climatéricas (Figuras 3 e 4). Comportamento semelhante ao das flores de esporinha foi observado na produção climatérica de etileno em orquídea Phalaenopsis tratada com os inibidores da ação do etileno STS e 1-MCP (Porat et al., 1995). Portanto, em esporinha, a senescência das flores é similar àquela presente em cravos e orquídeas, caracterizadas por picos na respiração e produção de etileno que coincidem com o início da senescência (Altvorst \& Bovy, 1995; Eason et al., 1997).

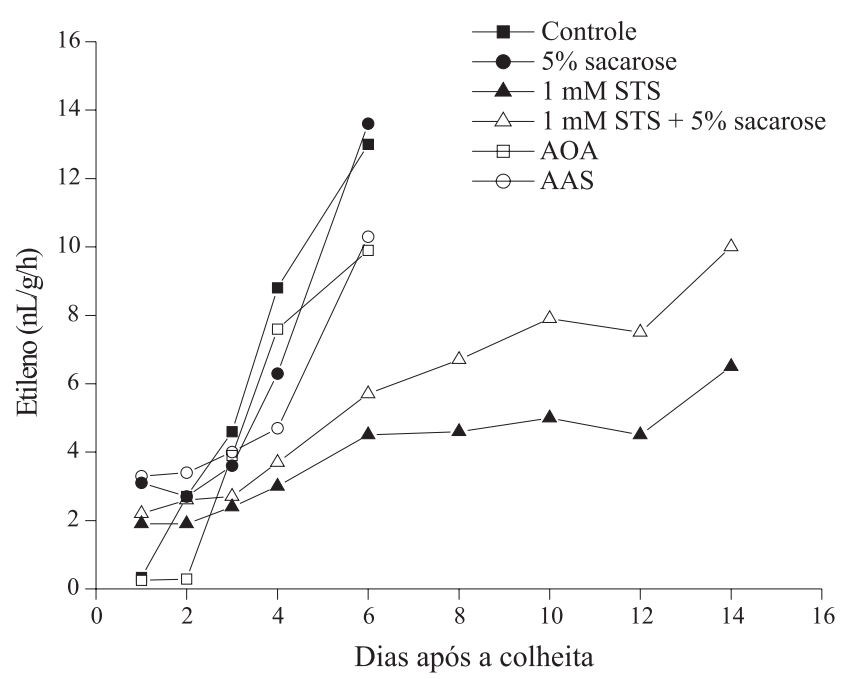

Figura 4. Produção de etileno em flores de esporinha (Consolida ajacis) após o condicionamento com 5\% de sacarose, $1 \mathrm{mM}$ de tiossulfato de prata (STS) ou $1 \mathrm{mM}$ de STS + 5\% sacarose por 30 minutos, e pulverizações com $2 \mathrm{mM}$ de ácido aminooxiacético (AOA) e $20 \mathrm{mM}$ de ácido acetilsalicílico (AAS). 


\section{Conclusões}

1. O condicionamento das flores de esporinha com $1 \mathrm{mM}$ de tiossulfato de prata (STS) por 30 minutos estende significativamente a longevidade, porém a adição de $5 \%$ de sacarose tem efeito negativo comparado ao STS isolado.

2. A pulverização das flores com $2 \mathrm{mM}$ de ácido aminooxiacético e $20 \mathrm{mM}$ ácido acetilsalicílico não prolonga a longevidade.

3. A flor de esporinha apresenta típica produção de etileno e respiração climatéricas durante a senescência.

4. A respiração e produção climatérica de etileno pela flor são inibidas pelo tratamento com STS.

\section{Agradecimentos}

À Capes e ao CNPq, pela concessão de bolsas a Tânia Forster Carneiro e Fernando Luiz Finger, respectivamente.

\section{Referências}

ABELES, F.B.; MORGAN, P.W.; SALTVEIT JUNIOR, M.E Ethylene in plant biology. $2^{\text {nd }}$ ed. San Diego: Academic, 1992 $414 \mathrm{p}$.

ALTVORST, A.C. van; BOVY, A.G. The role ethylene in the senescence of carnation flowers, a review. Plant Growth Regulation, v.16, p.43-53, 1995.

BICHARA, A.E.; STADEN J. van. The effect of aminooxyacetic acid and cytokinin combinations on carnation flower longevity. Plant Growth Regulation, v.13, p.161-167, 1993.

BOROCHOV, A.; SPIEGELSTEIN, H.; PHILOSOPH, H.S Ethylene and flower petal senescence: interrelationship with membrane lipid catabolism. Physiologia Plantarum, v.100, p.606-612 1997.

CHANASUT, U.; ROGERS, H.J.; LEVERENTZ, M.K.; GRIFFITHS, G.; THOMAS, B.; WGSTAFF, C.; STEAD, A.D Increasing flower longevity in Alstroemeria. Postharvest Biology and Technology, v.29, p.324-332, 2003.

EASON, J.R.; VRÉ, S.D.; HEYES, J.A. Physiological changes with Sandersonia aurantiaca flower senescence in response to sugar Postharvest Biology and Technology, v.12, p.43-50, 1997.

FINGER, F.L.; SANTOS, V.R.; MORAES, P.J.; BARBOSA, J.G. Pulsing with sucrose and silver thiosulfate extend the vase life of Consolida ajacis. Acta Horticulturae, v.543, p.63-67, 2001.
GOH, C.J.; HALEVY, A.H.; ENGEL, R.; KOFRANEK, A.M. Ethylene evolution and sensitivity orchid flowers. Scientia Horticulturae, v.26, p.57-67, 1985 .

ICHIMURA, K.; HIRAYA, T. Effects of silver tiosulfate complex (STS) in combination with sucrose on the vase life of cut sweet pea flowers. Journal of the Japanese Society for Horticultural Science, v.68, p.23-27, 1999

KETSA, S.; NARKBUA, N. Effect of aminooxyacetic acid and sucrose on vase life of cut roses. Acta Horticulturae, v.543, p.227231, 2001.

LESLIE, C.A.; ROMANI, R.J. Salicylic acid: a new inhibitor of ethylene biosynthesis. Plant Cell Reports, v.5, p.144-146, 1986. LORENZI, H.; SOUZA, H.M. Plantas ornamentais no Brasil: arbustivas, herbáceas e trepadeiras. 2.ed. São Paulo: Nova Odessa, 1999. 927p.

MALAMY, J.; KLESSING, D.F. Salicylic acid and plant disease resistance. The Plant Journal, v.2, p.643-654, 1992.

MOR, Y.; REID, M.S.; KOFRANEK, A.M. Pulse treatments with silver tiosulfate and sucrose improve the vase life of sweet peas. Journal of the Japanese Society for Horticultural Science, v.109, p.866-868, 1984

NOWAK, J.; RUDNICKI, R.M. Postharvest handling and storage of cut flowers, florist greens, and potted plants. Portland: Timber, 1990. 210p.

PORAT, R.; HALEVY, A.H.; SEREK, M.; BOROCHOV, A. An increase in ethylene sensitivity following pollination is the initial event triggering an increase in ethylene production and enhanced senescence of Phalaenopsis orchid flowers. Physiologia Plantarum, v.93, p.778-784, 1995 .

SEREK, M.; JONES, R.B.; REID, M.S. Role of ethylene in opening and senescence of Gladiolus sp. flowers. Journal of the American Society for Horticultural Science, v.119, p.1014-1019, 1994.

SHIMAMURA, M.; ITO, A.; SUTO, K.; OKABAYASHI, H.; ICHIMURA, K. Effects of $\alpha$-aminoisobutyric acid and sucrose on the vase life of hybrid Limonium. Postharvest Biology and Technology, v.12, p.247-253, 1997.

UDA, A.; YAMANAKA, M.; FUKUSHIMA, K.; KOYAMA, Y. Effects of various concentrations and duration of treatment with silver tiosulfate complex (STS) solutions on Ag absorption, distribution, and the vase life of cut carnations. Journal of the Japanese Society for Horticultural Science, v.64, p.927-933, Japan 1997.

VEEN, H. Silver tiosulfate: an experimental tool in plant science. Scientia Horticulturae, v.20, p.211-224, 1983.

WOLTERING, E.J. Effects of ethylene on ornamental pot plants: a classification. Scientia Horticulturae, v.31, p.282-294, 1987.

WOLTERING, E.J.; DOORN, W.G. van. Role of ethylene in senescence of petals-morphological and taxonomical relationships. Journal of Experimental Botany, v.39, p.1605-1616, 1988.

Recebido em 8 de outubro de 2003 e aprovado em 29 de março de 2004 